\title{
Minimally invasive operation for congenital heart disease: A sex-differentiated approach
}

\author{
Vladimiro L. Vida, MD, PhD, ${ }^{\mathrm{a}}$ Massimo A. Padalino, MD, PhD,${ }^{\mathrm{a}}$ Giovanna Boccuzzo, MPH, \\ Altin A. Veshti, MD, ${ }^{\mathrm{a}}$ Simone Speggiorin, MD, ${ }^{\mathrm{b}}$ Gianclaudio Falasco, MD, MPH, ${ }^{\mathrm{b}}$ and \\ Giovanni Stellin, MD ${ }^{\mathrm{a}}$
}

Objectives: Since 1996, we have routinely used a minimally invasive sex-differentiated surgical approach for surgical repair of various simple congenital heart diseases, mostly including a right anterior minithoracotomy in female subjects and a midline ministernotomy in male subjects.

Methods: Between August 1996 and December 2004, all patients who underwent a sex-differentiated surgical approach were included. Hospital results were compared with those of a group undergoing full sternotomy (control subjects). Patients' clinical conditions and satisfaction at follow-up were evaluated.

\begin{abstract}
Results: Three hundred eight patients underwent the sex-differentiated surgical approach: (1) minithoracotomy in $147(47.7 \%)$ and (2) ministernotomy in $161(52.3 \%)$. Thirty patients had a full sternotomy for atrial septal defect closure. The most common diagnosis was an atrial septal defect (231 [75\%] patients). None of the patients required an extension of the surgical access. There were neither major complications nor hospital deaths. All patients were discharged home without residual defects. Median follow-up time was 71.5 months (range, 48.2-85.7 months). There were no late deaths. No scoliosis, asymmetric breast development, or lactation problems were reported in the minithoracotomy group. Twenty-five (17\%) of 147 patients with minithoracotomies complained of a trivial, persistent ( $<6$ months), sensitive skin deficit in the mammary area, most often localized at the inferomedial quadrant. The vast majority of patients (296 [96\%] 308 patients) were in New York Heart Association class I, and $282(91.5 \%)$ of 308 patients were satisfied with the cosmetic result of the operation.
\end{abstract}

Conclusions: The sex-differentiated surgical approach for simple congenital heart disease is a safe procedure, providing both excellent functional and cosmetic results. Anterolateral minithoracotomy is a valid and highly appreciated procedure in female patients.

Improved surgical results in patients with simple congenital heart disease (sCHD) have stimulated surgeons to adopt minimally invasive techniques, ${ }^{1-8}$ with the aim of combining a good functional outcome with a better cosmetic result. Since 1996, we have adopted a minimally invasive sex-differentiated surgical approach by using a right anterior minithoracotomy in female subjects with an atrial septal defect (ASD) and a midline ministernotomy in male subjects with sCHD or female subjects with malformations other than ASDs.

We sought to analyze our experience with the sex-differentiated surgical approach for repair of sCHD in terms of hospital outcome and patient satisfaction.

\footnotetext{
From the Pediatric and Congenital Cardiac Surgery Unit ${ }^{\mathrm{a}}$ and the Departments of Anesthesia ${ }^{\mathrm{b}}$ and Statistics, ${ }^{\mathrm{c}}$ University of Padua, Padua, Italy.

Received for publication Sept 22, 2008; revisions received Jan 14, 2009; accepted for publication March 8, 2009.

Address for reprints: Giovanni Stellin, MD, Pediatric and Congenital Cardiac Surgery Unit, University of Padua, Via Giustiniani 2, 35128-Padua, Italy (E-mail: giovanni. stellin@unipd.it).

J Thorac Cardiovasc Surg 2009;138:933-6

$0022-5223 / \$ 36.00$

Copyright (C) 2009 by The American Association for Thoracic Surgery

doi:10.1016/j.jtcvs.2009.03.015
}

\section{MATERIALS AND METHODS}

Review of medical records was approved by the hospital committee on clinical investigation. Individual patients were not identified, and the need for patient consent was waived.

We included all patients who underwent the sex-differentiated surgical approach between August 1996 and December 2004. Thirty patients who did not request a minimally invasive approach and underwent conventional full sternotomy for ASD closure in the same time frame were selected as control subjects.

Patients were all managed under the same postoperative practice guidelines, which included early extubation ( $<6$ hours after surgical intervention) and early discharge from the intensive care unit ( $<24$ hours). As part of the program, all the patients were followed with a physical examination 1 month, 1 year, and 3 years after surgical intervention to assess the quality of the cosmetic result. In patients with minithoracotomies, particular care was taken to exclude the presence of scoliosis, restriction of shoulder motility, and sensibility deficit at the mammary area. Late results of surgical repair and patient satisfaction were also evaluated by means of direct contact with the patient or a telephone interview.

\section{Surgical Technique}

In patients with minithoracotomies, we used a 4- to 5-cm semilunar incision in the sulcus of the right breast (Figure 1, A), entering the chest in the fourth intercostal space. In the prepuberty age group the incision was kept very low under the right nipple to avoid any possible future interference with breast development. In patients with ministernotomies, the skin incision was 4 to $5 \mathrm{~cm}$ long in the midline of the chest, with its superior extension at or below the nipple level. The sternum was then longitudinally divided in its lower third and retracted (Figure 1,B). 


\section{Abbreviations and Acronyms \\ ASD = atrial septal defect \\ $\mathrm{IVF}=$ induced ventricular fibrillation \\ $\mathrm{sCHD}=$ simple congenital heart disease}

Mild hypothermic (rectal temperature of $34^{\circ} \mathrm{C}$ ) cardiopulmonary bypass with direct aortic and bicaval cannulation was routinely used. Assisted venous drainage was adopted to minimize the size of tubing and venous cannulas. Ventricular fibrillation was induced with an epicardial lead (Stocker Instrument Fibrillator) during repair in all patients with minithoracotomies. In patients with ministernotomies, conventional aortic crossclamping or induced ventricular fibrillation (IVF) was used according to the surgeon's preference.

During IVF, particular care was taken during the procedure to avoid pump suctioning into the left atrium. Furthermore, all patients weighing more than $5 \mathrm{~kg}$ of body weight were monitored in the operating room with transesophageal echocardiographic analysis, especially at the time of deairing to exclude any possible air in the left heart cavities at the time the heart start to eject. Intraoperative epicardial echocardiographic analysis was performed only in selected patients at less than $5 \mathrm{~kg}$ of body weight. ${ }^{9}$

Continuous variables were summarized as medians and interquartile ranges. The $\chi^{2}$ test was used for categorical variables, and the KruskalWallis test was used for continuous variables.

\section{RESULTS}

\section{Hospital Outcomes}

Three hundred eight patients underwent the minimally invasive sex-differentiated surgical approach (minithoracotomy, 147 [47.7\%] patients; ministernotomy, 161 [52.3\%] patients). The most common diagnosis in the sex-differentiated surgical approach group was secundum ASD (ASD II) in $231(75 \%)$ patients. The other most frequent diagnoses included ventricular septal defect (27 [8.8\%] patients), sinus venosus-type ASD (19 [6.1\%] patients), and partial atrioventricular canal defects (19 [6.1\%] patients). Cannulation was achieved through the chest in all patients. Assisted venous drainage was used, mainly in the last 3 years, with a median vacuum pressure of $35 \mathrm{~mm} \mathrm{Hg}$ (range, $20-50 \mathrm{~mm} \mathrm{Hg}$ ). Operative times were significantly longer in patients who underwent the sex-differentiated surgical approach, especially in the ministernotomy group during the first part of our experience (Table 1). None of the patients required conversion to a classic full sternotomy or a larger thoracotomy. None of our patients who had IVF showed decreased cardiac function at the postoperative transesophageal echocardiographic analysis requiring major postoperative inotropic support.

There were no hospital deaths and no major surgical/postoperative neurologic complications. All patients were discharged home in good clinical condition without residual intracardiac defects (Table 1).

\section{Follow-up}

Follow-up was $100 \%$ complete. At last follow-up (median, 71.5 months; range, 48.2-85.7 months), there were no late deaths. Two hundred ninety-six $(96 \%)$ of 308 patients were in New York Heart Association class I, and 12 $(4 \%)$ adult patients were in New York Heart Association class II, referring to mild limitation to activity.

At physical examination, $25(17 \%)$ of 147 patients with minithoracotomies complained of a mild, temporary $(<6$ months after surgical intervention), sensitive skin deficit in the mammary area, most often localized at the inferomedial quadrant of the mammary area (Figure 2). No shoulder movement deficit or scoliosis was detected.

Forty-one $(37 \%)$ of the 109 female patients who underwent minithoracotomy before puberty had breast development, which was completed in 13 of them who were older than 16 years of age. None of them had asymmetric development. No lactation problems were reported in 7 patients with minithoracotomies who underwent pregnancy.

The majority of patients (282/308 [91.5\%] 308 patients) were satisfied with the cosmetic result of the operation: the satisfaction rate was greater in patients with minithoracotomies when compared with that in patients with ministernotomies (140/147 [95.2\%] vs 142/161 [88.2\%], $P=.02)$. The reasons for nonsatisfaction were the presence of a "too long/ visible scar" in 18 patients ( 4 in the minithoracotomy group and 14 in the ministernotomy group) or a cheloid at the
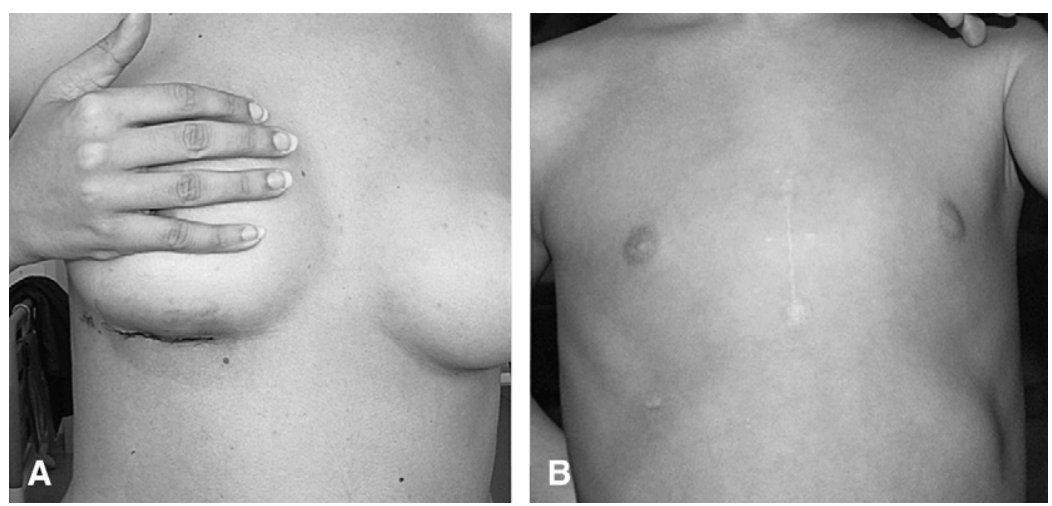

FIGURE 1. Postoperative images: A, 29-year-old woman who underwent atrial septal defect closure through a right anterior minithoracotomy; B, 5-year-old boy who underwent ventricular septal defect closure through a midline ministernotomy. 
TABLE 1. Patient's characteristics and hospital outcomes

\begin{tabular}{|c|c|c|c|c|}
\hline \multirow[b]{2}{*}{ Variables } & \multicolumn{2}{|c|}{ Sex-differentiated surgical approach group $(\mathbf{n}=\mathbf{3 0 8})$} & \multirow[b]{2}{*}{ Control group $(\mathbf{n}=\mathbf{3 0})$} & \multirow[b]{2}{*}{$P$ value } \\
\hline & MT $(n=147)$ & MS $(\mathbf{n}=161)$ & & \\
\hline Median age at operation (mo), Q1-Q3 & $72(36-156)$ & $48(20-108)$ & $66(24-228)$ & $.005 \ddagger$ \\
\hline Weight at operation $(\mathrm{kg}), \mathrm{Q} 1-\mathrm{Q} 3$ & $21(14-47.5)$ & $17.7(10.6-29)$ & $20(12.3-50)$ & $.005 \ddagger$ \\
\hline Female sex, no. $(\%)$ & $146(99)$ & $45(28)$ & $14(47)$ & $.0001^{*}$ \\
\hline CPB time (min), Q1-Q3 & $31(25-45)$ & $43(29-58)$ & $33(24-44)$ & $<.0001 \ddagger$ \\
\hline CCT, no. $(\%)$ & 0 & $46(28)$ & $23(77)$ & $<.0001 \dagger$ \\
\hline CCT (min), Q1-Q3 & - & $36(27-47)$ & $22(16-36)$ & $.002 \ddagger$ \\
\hline IVF, no. $(\%)$ & $147(100)$ & $115(71)$ & $7(23)$ & $<.0001^{*}$ \\
\hline IVF time (min), Q1-Q3 & $11(8-20)$ & $11(8-15)$ & $7(5-10)$ & $.01 \ddagger$ \\
\hline Assisted venous drainage, no. $(\%)$ & $37(25)$ & $25(15)$ & 0 & $.002 \dagger$ \\
\hline Incidence of minor arrhythmias, $\|$ no. $(\%)$ & 0 & $3(1.8)$ & 0 & - \\
\hline $\begin{array}{l}\text { Pericardial effusion requiring } \\
\text { drainage, no. }(\%)\end{array}$ & 0 & $2(1.2)$ & 0 & - \\
\hline Hospital stay (d), Q1-Q3 & $6(5-6)$ & $6(5-7)$ & $6(5-7)$ & $0.08 \ddagger \S$ \\
\hline
\end{tabular}

incision level in 8 patients ( 3 in the minithoracotomy group and 5 in the ministernotomy group).

\section{DISCUSSION}

Surgical intervention for SCHD has changed during the last decade, during which different surgical techniques have been developed with the aim of combining good functional and cosmetic results.

Hagl and colleagues, ${ }^{10}$ in 2001 , demonstrated that a full sternotomy is not always necessary for the correction of sCHD, and other institutions have reported excellent results in the correction of sCHD by means of ministernotomy. ${ }^{6-11}$

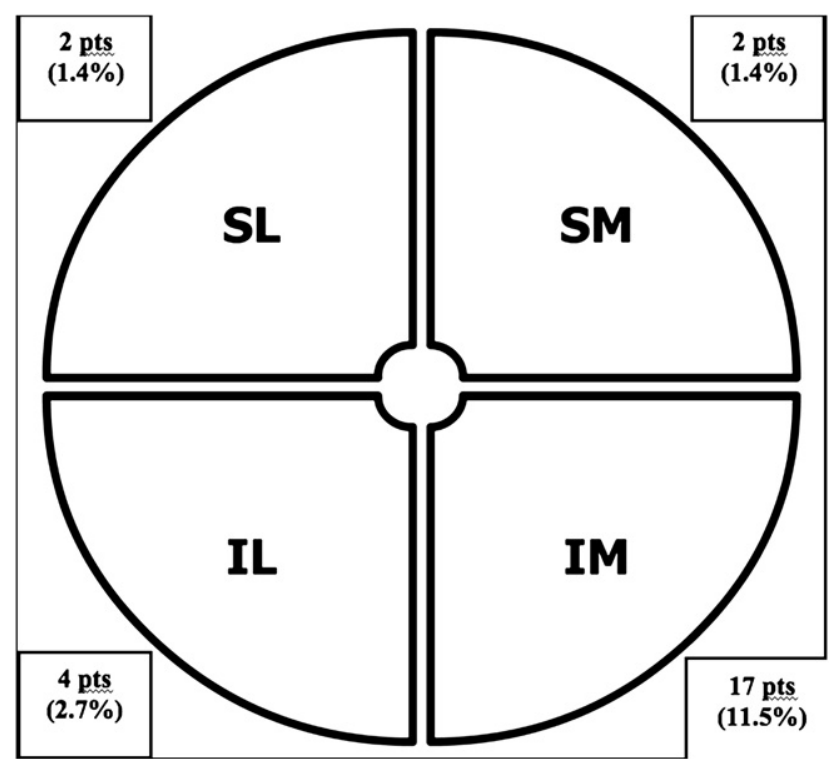

FIGURE 2. Distribution of the sensibility deficit of the mammary area (in quadrants) at follow-up within the $25(17 \%)$ of 147 patients who underwent a right anterior minithoracotomy. $S L$, Superolateral; $S M$, superomedial; $I L$, inferolateral; $I M$, inferomedial.
Furthermore, in other centers the use of a right anterolateral thoracotomy was advocated many years ago, ${ }^{4}$ and since then, several authors have reported its use for repair of both sCHD and complex congenital heart disease. ${ }^{12-15}$

Since 1996, we have routinely adopted a minimally invasive sex-differentiated surgical approach, offering minithoracotomy to female patients because the incision remains within the submammary sulcus and aortic crossclamping is not required.

Nonetheless, right breast asymmetry has been reported in patients with minithoracotomy. ${ }^{4,14}$ Our results with limited minithoracotomy show $95 \%$ patient satisfaction with no evidence of scoliosis, restriction to shoulder movement, lactation problems, or permanent neurosensorial deficit at the mammary area.

IVF has been used in our institution since 1991 for correcting SCHDs. The routine use of short periods of IVF in association with mild systemic hypothermia ${ }^{16,17}$ has been proved a safe and effective strategy when, because of a minimal skin incision, the crossclamping of the aorta might be cumbersome. On the other hand, ministernotomies were performed in male patients or in patients with diseases other than ASD because, according to our experience, it can guarantee a better exposure to the ascending aorta when crossclamping is required.

In conclusion, the sex-differentiated surgical approach for sCHD is safe and effective, producing functional results comparable with those of a classic surgical approach, with a high rate of subjective satisfaction between our patients.

\section{References}

1. Cremer TJ, Boning A, Anssar M, Kim PY, Pethig K, Harringer W, et al. Different approaches for minimally invasive closure of atrial septal defects. Ann Thorac Surg. 1999;67:1648-52.

2. Byrne JG, Adams DH, Mitchell ME, Cohn LH. Minimally invasive direct access for repair of atrial septal defect in adults. Am J Cardiol. 1999;84:919-22. 
3. Bichell DP, Geva T, Bacha EA, Mayer JE, Jonas RA, del Nido PJ. Minimal access approach for the repair of atrial septal defect: the initial 135 patients. Ann Thorac Surg. 2000;70:115-8.

4. Abdel-Rahman U, Wimmer-Greinecker G, Matheis G, Klesius A, Seitz U, Hofstetter R, et al. Correction of simple congenital heart defects in infants and children through a minithoracotomy. Ann Thorac Surg. 2001;5:1645-9.

5. Nicholson IA, Bichell DP, Bacha EA, del Nido PJ. Minimal sternotomy approach for congenital heart operations. Ann Thorac Surg. 2001;71:469-72.

6. Del Nido PJ, Bichell DP. Minimal access surgery for congenital heart defects. Semin Thorac Cardiovasc Surg Pediatr Card Annu. 1998;1:75-80.

7. Oiwa H, Ishida R, Sudo K. Systematic traction techniques in minimal access pediatric cardiac surgery. Ann Thorac Surg. 2004;78:1856-7.

8. Ak K, Aybek T, Wimmer-Greinecker G, Ozaslan F, Bakhtiary F, Moritz A, et al. Evolution of surgical techniques for atrial septal defect repair in adults: a 10 year single center experience. J Thorac Cardiovasc Surg. 2007;134:757-64.

9. Ungerleider RM, Greeley WJ, Sheikh KH, Philips J, Pearce FB, Kern FH, et al. Routine use of intraoperative epicardial echocardiography and Doppler color flow imaging to guide and evaluate repair of congenital heart lesions. A prospective study. J Thorac Cardiovasc Surg. 1990;100:297-309.

10. Hagl C, Stock U, Haverich A. Steinhoff. Evaluation of different minimally invasive techniques in pediatric cardiac surgery. Is full sternotomy always a necessity? Chest. 2001;119:622-7.
11. Laussen PC, Bichell DP, McGowan FX, Zurakowski D, DeMaso DR, del Nido PJ. Postoperative recovery in children after minimum versus full length sternotomy. Ann Thorac Surg. 2000;69:591-6.

12. Ando M, Takahashi Y, Kikuchi T. Short operation time: an important element to reduce operative invasiveness in pediatric cardiac surgery. Ann Thorac Surg. 2005;80:631-5.

13. Dabritz S, Sachweh J, Walter M, Messmer BJ. Closure of atrial septal defects via a limited right anterolateral thoracotomy as a minimal invasive approach in female patients. Eur J Cardiothorac Surg. 1999;15:18-23.

14. Lancaster LL, Mavroudis C, Rees AH, Slater AD, Ganzel BL, Gray LA. Surgical approach to atrial septal defect in female. Right thoracotomy versus sternotomy. Am Surg. 1990;56:218-22.

15. Bleiziffer S, Schreber C, Burgkart R, Regenfelder F, Kostonly M, Libera P, et al. The influence of right anterolateral thoracotomy in prepubescent female patients on late breast development and on the incidence of scoliosis. J Thorac Cardiovasc Surg. 2004;127:1474-80.

16. Cox JL, Anderson RW, Pass HI, Currie WD, Roe CR, Mikat E, et al. The safety of induced ventricular fibrillation during cardiopulmonary bypass in nonhypertrophied hearts. J Thorac Cardiovasc Surg. 1977;74:423-32.

17. Vinas JF, Fewel JG, Arom KV, Trinkle JK, Grover FL. Effects of systemic hypothermia on myocardial metabolism and coronary blood flow in fibrillating heart. J Thorac Cardiovasc Surg. 1979;77:900-7. 